\title{
Sunitinib Induced Hypocalcemia and its Potential Role in the Treatment of Refractory Hypercalcemia
}

\author{
Alexandraki KI*, Kaltsatou M, Chatzellis E, Karnezis J, Tsoli M, \\ Chrysochoou M, Boutzios G and Kaltsas G \\ Clinic of Endocrine Oncology, Section of Endocrinology, Department of \\ Pathophysiology, National and Kapodistrian University of Athens Medical School, \\ Laiko University Hospital, Athens, Greece
}

\section{Research Article \\ Volume 1 Issue 1}

Received Date: February 14, 2017

Published Date: March 27, 2017

*Corresponding author: Krystallenia I Alexandraki, Endocrine Unit, Department of Pathophysiology, National University of Athens, Mikras Asias 75, 115 27, Athens, Greece, Tel: 0030 2107462657; Fax: 0030 2107462664; E-mail: alexandrakik@gmail.com

\section{Abstract}

Background: Sunitinib, an oral multi-targeted tyrosine kinase inhibitor has been approved for the treatment of advanced pancreatic neuroendocrine neoplasms (pNENs).

Aim: To describe a series of 12 patients with pNENs on sunitinib who developed hypocalcemia.

Patients and Methods: Three patients developed hypocalcemia, grade 4, 1 and 2 respectively.

Results: A 58-year-old man with a stage IV, grade 2, initially non-functioning pNEN (NFpNEN), developed disease progression with concomitant hypersecretion of parathyroid hormone related-peptide (PTHrP) and uncontrolled hypercalcemia. After one month of sunitinib treatment, grade 4 hypocalcemia $(<6 \mathrm{mg} / \mathrm{dl})$ developed. Following treatment reinstitution at a lower dose, hypercalcemia became easily controlled. Another two patients with NFpNEN treated with sunitinib developed a grade $1(8.2 \mathrm{mg} / \mathrm{dl})$ non-symptomatic and a grade $2(7.2 \mathrm{mg} / \mathrm{dl})$ symptomatic hypocalcemia, both nine months after sunitinib was initiated.

Conclusions: Sunitinib-induced hypocalcemia may be a common side-effect that could be of therapeutic significance in patients with pNEN and refractory PTHrP-related hypercalcemia.

Keywords: Sunitinib; Hypocalcemia; Pancreatic Neuroendocrine Neoplasm; Tyrosine Kinase Inhibitors 


\section{Open Access Journal of Endocrinology}

\section{Introduction}

Sunitinib is an orally administered multi-targeted tyrosine kinase inhibitor (TKI) with anti-angiogenic and antitumor activity that targets platelet-derived growth factor receptor (PDGFR), vascular endothelial growth factor receptors (VEGFRs) and a number of other receptors that play a role in both tumor angiogenesis and tumor cell proliferation [1-2]. The simultaneous inhibition of these targets leads to both reduced tumor vascularization and cancer cell death, and ultimately tumor shrinkage.

Sunitinib has been licensed for the treatment of metastatic renal cell carcinoma (RCC) and gastrointestinal stromal tumors (GIST) [3-5]. Recently, the European Medicines Agency (EMA) and United States (US) Food and Drug Administration (FDA) based on the results of a phase 3 trial approved the drug for the treatment of patients with unresectable, locally advanced or metastatic well-differentiated pancreatic neuroendocrine neoplasms (pNENs) with disease progression [6].

In that study, which evaluated 86 patients for a median duration of 4.6 months (range: 0.4-17.5), 19 patients $(22 \%)$ were treated with sunitinib for more than one year with the most prevalent side effects being gastrointestinal, asthenia and fatigue [6]. Calcium metabolism disorders, both hypocalcemia and hypercalcemia have been reported in sunitinib treated patients [3-5] whereas no case of hypocalcemia was recorded in pNEN patients [6]. Besides hypocalcemia, sunitinib may also induce additional side effects such as hypophosphatemia, hypomagnesemia, diarrhea, mucositis, hypoalbuminemia and deterioration of renal function, each of which could impact on calcium metabolism [3]. However, despite the fact that the hypocalcemic side effect of sunitinib is well described and anticipated, no case series with pNENs patients treated with sunitinib who developed hypocalcemia at an acute setting or during regular follow-up has been published so far.

We have documented one patient with pNEN and refractory hypercalcemia due to parathyroid hormone related peptide (PTHrP) secretion, who developed severe hypocalcemia grade 4 during sunitinib treatment. We advocate that sunitinib could be used as a therapeutic mean to control elevated serum calcium levels in similar settings. Subsequently, we retrospectively investigated our small series of patients with pNENs on sunitinib treatment, highlighting the relatively high prevalence of hypocalcemia in patients treated with this agent.

\section{Patients and Methods}

We have retrospectively analyzed 3 out of 12 (25\%) patients with pNENs who were treated with sunitinib and developed grade 4, 1, and 2 hypocalcemia respectively. The decision to initiate treatment with sunitinib was based on disease progression and/or intolerance to other treatments [6]. All toxicities were reported according to the Common Terminology Criteria for Adverse Events v4.03 (CTCAE) [7]. All patients were informed about the probable adverse events before sunitinib administration and an informed consent was obtained.

\section{Description of Cases}

Patient 1: A 58 year-old man presented with a long history of a grade 2 (Ki-67 labelling index [LI] 4\%), nonfunctioning pNEN (NFpNEN) with hepatic metastases. As depicted in Figure 1, he received several therapeutic schemes due to disease progression and during follow-up; he developed severe hypercalcemia due to PTHrP secretion from the primary tumor that was resistant to treatment with bisphosphonates, cinacalcet, octreotide LAR and glucocorticoids [8]. Consequent administration of peptide receptor radionucleotide treatment (PRRT), several chemotherapeutic agents including combinations of capecitabine / temozolomide and temozolomide / bevacizumab / everolimus and transcatheter arterial embolization (TAE) managed to temporarily control tumour growth and calcium levels.

Once further disease progression occurred, sunitinib was administered at a dose of $37.5 \mathrm{mg}$ daily. It should be noted that the patient did not receive bisphosphonate for 36 months prior to sunitinib initiation. One month later, he was urgently admitted to another hospital, due to dizziness and symptomatic grade 4 hypocalcemia [corrected according to albumin calcium levels $6.0 \mathrm{mg} / \mathrm{dl}$; normal range: 8.4-10.1 mg/dl according to CTCAE [10]. Sunitinib was discontinued and calcium was administered intravenously with subsequent normalization of serum calcium levels. Treatment with sunitinib was reinstituted at $25 \mathrm{mg}$ daily and 2 weeks later at the indicated daily dosage of $37.5 \mathrm{mg}$ with close calcium levels monitoring. However, no further effect on calcium homeostasis was noted during the rest of his treatment (Table 1). 


\section{Open Access Journal of Endocrinology}

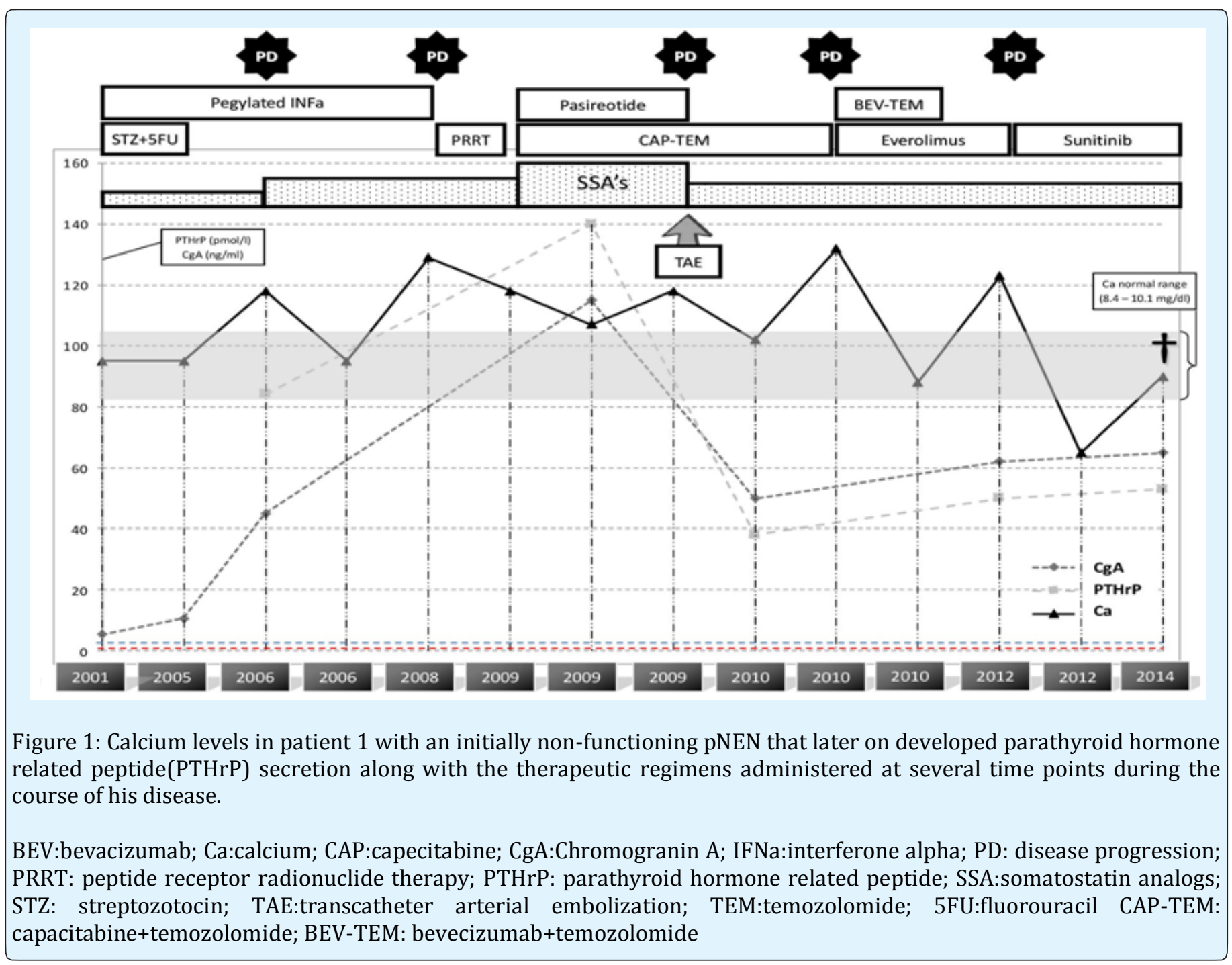

Patient 2: A 53-year-old man with Multiple Endocrine Neoplasia 1 (MEN-1) syndrome and a grade 1 (Ki-67 1\%), stage VI non-functioning pNEN was initially treated with a partial pancreatectomy and liver metastasectomy. He had previously undergone three and a half parathyroid gland resection and, was receiving stable doses of calcium gluconate and alfacalcidol to maintain normocalcemia. In addition, due to severe osteoporosis, $5 \mathrm{mg}$ of zolendronic acid was administered once yearly. Following a 34-month period of disease stabilization with lanreotide SR $120 \mathrm{mg}$ monthly, he developed disease progression and treatment with everolimus $10 \mathrm{mg}$ daily was co-administered. However, due to intolerance and emerging anemia, everolimus was changed to sunitinib $37.5 \mathrm{mg}$ daily with subsequent disease stabilization. Regular follow-up examinations occurred every three months but nine months later, grade 1 (calcium levels $8.2 \mathrm{mg} / \mathrm{d}$; normal range $8.4-10.1 \mathrm{mg} / \mathrm{dl}$ ) hypocalcemia developed without any alteration of his treatment with calcium gluconate and alfacalcidol. This mild and asymptomatic hypocalcemia resolved by increasing the dose of calcium gluconate and alfacalcidol to $2 \mathrm{~g}$ and $2 \mathrm{mcg}$ daily respectively, while maintaining the same dose of sunitinib. It is important to note that the patient had not received zolendronic acid for 11 months prior to the hypocalcemic event.

Patient 3: A 51-year-old man with a stage IV, grade 1 (Ki$671 \%$ ), $3 \mathrm{~cm}, \mathrm{NFpNEN}$ at the tail of the pancreas was initially treated with pancreatectomy and resection of liver metastases followed by radiofrequency (RF) ablation of recurrent liver metastases along with octreotide long acting release (LAR) (30 mg every 28 days). Due to disease progression, sunitinib, administered $37.5 \mathrm{mg}$ once daily, lead to disease stabilization, but nine months later he was urgently admitted to another hospital due to dizziness and symptomatic grade 2 hypocalcemia (serum calcium levels $7.1 \mathrm{mg} / \mathrm{dl}$; normal range: $8.4-10.1 \mathrm{mg} / \mathrm{dl}$ ). 


\section{Open Access Journal of Endocrinology}

He was subsequently treated with calcium $1 \mathrm{~g}$ twice daily and alfcalcidol $1 \mathrm{mcg}$ twice daily while a sunitinib $37.5 \mathrm{mg}$ dose was omitted every third day. Since then, the patient has remained normocalcemic.

Two of our patients with a NFpNEN, developed hypocalcemia nine months post-sunitinib administration while the patient with the paraneoplastic hypercalcemia due to PTHrP hypersecretion developed this side effect within one month of treatment initiation. Although the number of cases studied is small and the interval of hypocalcemia development was variable, hypocalcemia could not be predicted by pre-treatment calcium levels. The severity of hypocalcemia ranged from mild to life threatening without being related to either the dose of sunitinib or to the duration of treatment. In all cases, treatment discontinuation or dose alteration along with adequate calcium supplementation sufficed in restoring normocalcemia and treatment could be re-initiated at a lower dose titrated to serum calcium levels.

\section{Discussion}

In the present small series of 12 patients with pNENs treated with sunitinib, three (25\%) developed variable degrees of hypocalcemia [9] but in one case the hypocalcemic effect of sunitinib is highlighted, introducing a new concept of a potentially beneficial effect of sunitinib induced hypocalcemia in patients with retractable hypercalcemia secondary to PTHrP secretion. In two patients, hypocalcemia was clinically evident and biochemically confirmed prior the development of any clinical symptom/sign during regular follow-up. These findings are in accordance with those derived from the literature describing a $13-43 \%$ drop in serum calcium levels in patients treated with sunitinib [9], but to date, there is no case report describing the beneficial role of this side effect of sunitinib or another TKI agent.

The initial drug supplementary protection certificate (SPC) included hypocalcemia per se as a side effect found mostly as part of the uncommonly encountered tumor lysis syndrome (TLS). However, a recent revised monograph of the product reported that following treatment with sunitinib, grade $1 / 2$ hypocalcemia may be found in up to $34 \%$ of patients with pNENs and in $42-43 \%$ of patients with malignant renal-cell carcinoma(MRCC) whereas only $1 \%$ of cases could be grade 3/4 [3]. Following this observation, an additional small, phase 1 trial evaluating sunitinib in combination with radiation therapy for primary or metastatic central nervous system malignancies reported a $13 \%$ prevalence of grade $1 / 2$ hypocalcemia [9]. Most cases of sunitinib-related hypocalcemia were easily managed through dose interruption or dose modification. This hypocalcemic effect of sunitinib could be attributed to an antiresorptive activity of the drug reported in patients with RCC and prostate cancer with bone metastasis $[10,11]$.

Several factors may induce or contribute to the development of hypocalcemia in patients with cancer. Hypoalbuminemia is common in critically ill patients, although low calcium levels are without clinical significance since the active fraction of calcium remains unaffected; nevertheless, there was no evidence of low serum albumin levels in our patient (Table 1) [12]. Similarly, hypomagnesemia, commonly found in patients with malignancies, may lead to hypocalcemia that is usually non-responsive to calcium and vitamin D administration [12]. Indeed, our patients had no evidence of an obvious cause of magnesium loss, either via the kidneys or the gastrointestinal system or through poor nutrition, although an antiresorptive activity of sunitinib inducing electrolytic imbalance cannot be excluded $[10,11]$. However, all patients responded promptly to calcium and vitamin D administration without concomitant magnesium supplementation. Moreover, in one recent study of patients with MRCC and bone metastases treated with TKIs, bisphosphonate treatment (in 10\% of them) was associated with increased rates of hypocalcemia, mostly seen in patients under non-VEGF therapy [13].

In our cohort, two patients were treated with bisphosphonates but this treatment seems not to have had impact on hypocalcemia since the interval between the bisphosphonates administration and the hypocalcemic event was too long. Other chemotherapeutic agents have been reported to induce hypocalcemia, either through cisplatin-induced hypomagnesemia, streptozotocin's direct pancreatic damage or 5-fluorouracil's and leucovorin's reduction of vitamin D production; however, in the present cases no such therapeutic schemes were given when hypocalcemia developed. Vitamin D deficiency is also a common cause of hypocalcemia; although it is not known whether sunitinib treatment can induce vitamin D deficiency. All our patients had vitamin D deficiency or insufficiency that was corrected with vitamin D supplementation (Table 1). The elevated alkaline phosphatase levels in the patient with the PTHrP-secreting p-NEN were possibly due to the bone lesions (brown tumours, BT) seen in the specific patient, as previously described [8], as well as to concomitant liver metastases. A different mechanism through which hypocalcemia can occur in cancer patients is through pancreatic damage and/or insufficiency or pancreatitis as recently documented [14]; however, none of the patients had clinical or biochemical evidence of pancreatic dysfunction. Finally, although hypocalcemia may be due to osteoblastic metastases which can be found 


\section{Open Access Journal of Endocrinology}

in patients with pNENs and in patients with the TLS, this was not the case since none of our patients had documented bone metastases [12,15]. A detailed biochemical and hormonal profile of calcium metabolism to provide further information on the pathogenesis of sunitinib induced hypocalcemia was not performed since two of our patients were admitted in other hospitals and necessitated urgent treatment. However, it is also likely that sunitinib may cause hypocalcemia through mechanisms that have not been fully elucidated.

\begin{tabular}{|c|c|c|c|c|c|c|c|}
\hline \multirow{2}{*}{ Parameters } & \multirow{2}{*}{$\begin{array}{l}\text { Reference } \\
\text { Range }\end{array}$} & \multicolumn{2}{|c|}{ Patient 1* } & \multicolumn{2}{|c|}{ Patient 2} & \multicolumn{2}{|c|}{ Patient 3} \\
\hline & & $\begin{array}{l}\text { Before } \\
\text { sunitinib }\end{array}$ & $\begin{array}{l}\text { After } \\
\text { sunitinib }\end{array}$ & $\begin{array}{l}\text { Before } \\
\text { sunitinib }\end{array}$ & $\begin{array}{l}\text { After } \\
\text { sunitinib }\end{array}$ & $\begin{array}{c}\text { Before } \\
\text { sunitinib }\end{array}$ & $\begin{array}{c}\text { After } \\
\text { sunitinib }\end{array}$ \\
\hline Serum Calcium levels** & $\begin{array}{c}8.4-10.1 \\
\mathrm{mg} / \mathrm{dL}\end{array}$ & 12.35 & 6 & 9.2 & 8.2 & 8.8 & 7.1 \\
\hline $\begin{array}{c}\text { Serum Magnesium } \\
\text { levels }\end{array}$ & $\begin{array}{c}1.58-2.55 \\
\mathrm{mg} / \mathrm{dL}\end{array}$ & ND & ND & 1.7 & 1.8 & ND & 2.2 \\
\hline Serum Albumin levels & $3.7-5.1 \mathrm{~g} / \mathrm{dL}$ & 3.4 & 3.7 & 4 & 3.6 & 4.4 & 4.2 \\
\hline Serum Phosphate levels & $2.7-4.5 \mathrm{mg} / \mathrm{dL}$ & 2.08 & ND & 2.8 & 2.6 & 4 & 4.5 \\
\hline $\begin{array}{l}\text { Serum alkaline } \\
\text { phosphatase }\end{array}$ & 53-128 IU/L & 240 & 392 & 65 & 57 & 61 & 48 \\
\hline $\begin{array}{c}\text { Serum alanine } \\
\text { aminotransaminase } \\
\text { (ALT) }\end{array}$ & $5-35 \mathrm{U} / \mathrm{L}$ & 15 & 27 & 23 & 33 & 7 & 19 \\
\hline $\begin{array}{c}\text { Serum aspartate } \\
\text { aminotransferase (AST) }\end{array}$ & $5-45 \mathrm{U} / \mathrm{L}$ & 20 & 50 & 28 & 25 & 13 & 29 \\
\hline $\begin{array}{l}\text { Serum gamma-glutamyl } \\
\text { transpeptidase }\end{array}$ & $12-64 \mathrm{U} / \mathrm{L}$ & 235 & 436 & 58 & 44 & 12 & 17 \\
\hline \multirow{2}{*}{$\begin{array}{c}\text { Serum } 25(\mathrm{OH}) \text { Vitamin } \\
\text { D3 levels at first } \\
\text { evaluation*** }\end{array}$} & $\begin{array}{c}\text { Deficiency }<10 \\
\mathrm{ng} / \mathrm{ml}\end{array}$ & \multirow[t]{2}{*}{6.8} & \multirow[t]{2}{*}{ ND } & \multirow[t]{2}{*}{10} & \multirow[t]{2}{*}{21} & \multirow[t]{2}{*}{13.2} & \multirow[t]{2}{*}{ ND } \\
\hline & $\begin{array}{l}\text { Insufficiency } \\
10-28 \mathrm{ng} / \mathrm{ml}\end{array}$ & & & & & & \\
\hline Serum PTH levels & $10-65 \mathrm{pg} / \mathrm{mL}$ & $<2$ & $<2$ & 50 & 71 & 18.6 & 25 \\
\hline Serum Creatinine levels & $0.6-1.2 \mathrm{mg} / \mathrm{dL}$ & 0.79 & 0.8 & 0.8 & 0.7 & 1.1 & 1.4 \\
\hline $\begin{array}{c}\text { Urinary } 24 \text {-hr calcium } \\
\text { excretion }\end{array}$ & $\begin{array}{l}100-300 \\
\mathrm{mg} / 24 \mathrm{hr}\end{array}$ & ND & ND & 90 & 208 & ND & ND \\
\hline
\end{tabular}

Table 1. Biochemical parameters before treatment with sunitinib and after documentation of hypocalcemia in the three index cases.

PTH: parathyroid hormone; ND: not done; hr: hour; *the specific patient had brown tumors due to PTHrP secretion; ${ }^{* *}$ calcium levels were corrected by albumin levels; ***all the patients were receiving Vitamin D supplements by the time of the hypocalcemic effect with values $>20 \mathrm{ng} / \mathrm{ml}$. 


\section{Open Access Journal of Endocrinology}

In two of our patients, hypocalcemia developed nine months post-sunitinib administration while in the patient with the paraneoplastic hypercalcemia this adverse reaction occurred within one month. Although the number of patients studied is small, the interval of hypocalcemia development is variable. Moreover, its severity can range from mild to life threatening without being related to either the dose or the duration of treatment with sunitinib. However, in all cases, treatment discontinuation of the drug with adequate calcium supplementation usually sufficed restoring normocalcemia and treatment could be re-initiated at a lower dose titrated to serum calcium levels.

In conclusion, this small case series and review of the literature imply the necessity of a full calcium metabolic profile evaluation before the introduction of a TKI treatment and during follow-up. Hypocalcemia seems to be a common abnormality in patients with pNENs treated with sunitinib necessitating frequent and regular followup to identify this potential side effect and treat such patients promptly. However, in patients with refractory hypercalcemia due to hypersecretion of PTHrP, sunitinib induced hypocalcemia may be of therapeutic significance. Larger series are needed to confirm the effect of sunitinib on calcium levels and reveal the underlying pathophysiological mechanisms and its potential beneficial role in patients with refractory hypercalcemia. However, it should be highlighted that this is a single case report and the response could be anecdotal while additional evaluation studies are required.

\section{Acknowledgement}

Disclosure summary: There is no conflict of interest that could be perceived as prejudicing the impartiality of the research reported.

\section{References}

1. Mendel DB, Laird AD, Xin X, Louie SG, Christensen JG, et al. (2003) In vivo antitumor activity of SU11248, a novel tyrosine kinase inhibitor targeting vascular endothelial growth factor and platelet-derived growth factor receptors: determination of a pharmacokinetic/pharmacodynamic relationship. Clin Cancer Res 9(1): 327-337.

2. Laird AD, Christensen JG, Li G, Carver J, Smith K (2002) SU6668 inhibits Flk-1/KDR and PDGFRbeta in vivo, resulting in rapid apoptosis of tumor vasculature and tumor regression in mice. FASEB J 16(7): 681-690.
3. Sutent: Tyrosine Kinase Inhibitor, Anti-Tumour Agent. Quebec: CP Pharmaceuticals International CV, 2014.

4. Demetri GD, Garrett CR, Schöffski P, Shah MH, Leyvraz $S$, et al. (2012) Complete longitudinal analyses of the randomized, placebocontrolled, phase III trial of sunitinib in patients with gastrointestinal stromal tumor following imatinib failure. Clin Cancer Res 18(11): 3170-3179.

5. Goodman VL, Rock EP, Dagher R, Ramchandani RP, Abraham S, et al. (2007) Proval summary: sunitinib for the treatment of imatinib refractory or intolerant gastrointestinal stromal tumors and advanced renal cell carcinoma. Clin Cancer Res 13; $1367-1373$

6. Raymond E, Dahan L, Raoul JL, Bang YJ, Borbath I, et al. (2011) Sunitinib malate for the treatment of pancreatic neuroendocrine tumors. N Engl J Med 364(6): 501-513.

7. Common terminology criteria for adverse events ((CTCAE) v.4 data files) 2014.

8. Kanakis G, Kaltsas G, Granberg D, Grimelius L, Papaioannou D, et al. (2012) Unusual complication of pancreatic neuroendocrine $t$ umor presenting with malignant hypercalcemia. J Clin Endocrinol Metab 97(4): 627-631.

9. Wuthrick EJ, Kamrava M, Curran WJ Jr, Werner-Wasik M, Camphausen KA, et al. (2011) A phase 1b trial of the combination of the antiangiogenic agent sunitinib and radiation therapy for patients with primary and metastatic central nervous system malignancies. Cancer 117(24): 5548-5559.

10. Sahi C, Knox JJ, Hinder V, Deva S, Cole D, et al. (2009) The effects of sorafenib and sunitinib on bone turnover markers in patients with bone metastases from renal cell carcinoma. Journal of Clinical Oncology 27(15): e16145.

11. Beuselinck B, Wolter P, Karadimou A, Elaidi R, Dumez $\mathrm{H}$, et al. (2012) Oral tyrosine kinase inhibitors and bisphosphonates in advanced renal cell carcinoma with bone metastases. Br J Cancer 107(10): 16651671.

12. Manish S, Vecihi Batuman (2014) Hypocalcemia. Medscape.

13. McKay RR, Lin X, Perkins JJ, Heng DY, Simantov R, et al. (2014) Prognostic significance of bone metastases 


\section{Open Access Journal of Endocrinology}

and bisphosphonate therapy in patients with renal cell carcinoma. Eur Urol 66(3): 502-509.

14. Ready NE, Pang HH, Gu L, Otterson GA, Thomas, et al. (2015) Chemotherapy With or Without Maintenance Sunitinib for Untreated Extensive-Stage Small-Cell Lung Cancer: A Randomized, Double-Blind, PlaceboControlled Phase II Study-CALGB 30504 (Alliance). J Clin Oncol 33(15): 1660-1665.
15. Ruinemans GM, Balemans C, Mattijssen V, Wiersmavan Tilburg AJ, Smit HJ, et al. (2010) Fatal necrotizing pancreatitis during combined treatment with erlotinib and sunitinib. Lung Cancer 70(3): 364-365. 